\title{
Atrial Septal Defect in Patients Over 45 Years of Age
}

\author{
Merits of Surgical Versus Medical Therapy*
}

\author{
PHILLIP S. WOLF, JOHN H. K. VOGEL, RAY PRYOR, AND S. GILBERT BLOUNT, JR. \\ From the Division of Cardiology, Department of Medicine, University of Colorado Medical Center, \\ Denver, Colorado, U.S.A.
}

That patients with atrial septal defects may achieve considerable longevity has been well documented, the diagnosis having been verified in persons in the eighth and ninth decades (Roesler, 1934; Colmers, 1958; Cherniack, 1963; Novack et al., 1963; Ellis, Brandenburg, and Swan, 1960; Rodstein, Zeman, and Gerber, 1961; Kelly and Lyons, 1958). There is little question about the advisability of surgery in younger patients. Several reports of successful closure of these defects in older patients are also available (McGoon et al., 1959; Ellis et al., 1960; Taylor, Sanger, and Robicsek, 1963). While the surgical mortality figures from the reporting institutions are impressively low, the numbers of older patients reported are small, and the reports do not compare the merits of surgery with the natural history of this disorder. Our investigation was undertaken to assess the experience at this institution with older patients both with and without surgery.

\section{SubJeCts AND METHOdS}

All patients 45 years of age and older with secundum type atrial septal defects who have been followed at this institution were included. Except for one patient with coarctation of the aorta, no additional congenital defects were found. Of the 34 patients studied, 15 underwent surgical closure and 19 received medical management. No particular requirements were set in the selection of patients for operation. It is likely, however, that some were rejected as candidates because of pulmonary hypertension, others because of lack of symptoms, and others because they lacked enthusiasm for having an operation.

All patients had a history, physical examination, electrocardiogram, and radiological investigation. The diagnosis was established by: (1) direct visualization of the defect at operation (15 patients), (2) necropsy (6

Received July 24, 1967.

* Supported in part by USPHS Training Grant. patients), and/or (3) cardiac catheterization (29 patients). Cardiac catheterization was considered diagnostic $(22$ patients) if a minimum oxygen step-up of 1.5 vol. per cent from caval samples to right atrium was obtained. Hydrogen curves were positive in right atrium in all 11 patients tested, and verified the diagnosis in 4 of 7 patients in whom increases in oxygen content were nondiagnostic. The catheter crossed the atrial septum 13 times : 8 times from the left arm and twice from the right, and in the other three, the cut-down site was not specified.

The oxygen content was calculated by the method of Van Slyke and Neill (1924). Systemic arteriovenous oxygen difference $\left(\mathrm{Cav}_{\mathrm{O} 2}\right)$ was obtained from systemic arterial oxygen content and caval samples. The caval samples were expressed as an average of inferior vena caval oxygen content (two-thirds of total value) and superior vena caval content (one-third). The pulmonary $\mathrm{Ca} \bar{v}_{\mathrm{O} 2}$ was calculated as the difference in oxygen content between mixed venous and pulmonary venous blood (left atrial or systemic arterial samples). The normal mean systemic arterial saturation in this laboratory is $94 \cdot 1$ per cent (range $89 \cdot 2$ to $97 \cdot 3 \%$ ). In those instances where systemic arterial saturation was less than 90 per cent (13 patients), for purposes of calculation, a pulmonary venous saturation of 90 per cent was assumed. In 7 patients a pulmonary vein was entered and the saturation obtained therein was used for calculations. While it is conceded that such a manipulation may produce minor distortions in the calculation of blood flows, the error produced by unsaturation secondary to pulmonary disease is lessened. Dye curves in 5 subjects did not indicate a right-to-left shunt in any instance.

Employing these clinical and laboratory observations, the surgical group and the non-surgical group were then compared. When available, the same findings were assessed before and after operation to evaluate the success of surgery.

\section{RESULTS}

The average age in the surgical group ( $52 \cdot 3$ years) was appreciably lower than in those not operated 


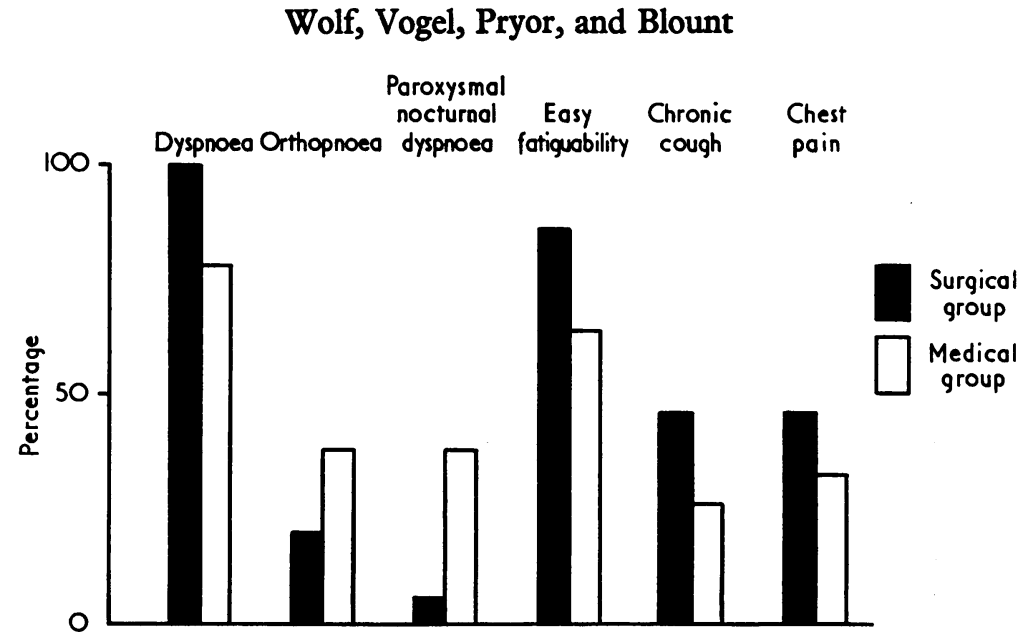

FIG. 1.-Incidence of symptoms in 15 patients who later underwent surgical closure of atrial septal defect and in 19 who received medical management.

upon (61.7 years). Follow-up data available in 31 of the 34 patients were considered complete if the patient had been evaluated within six months of the completion of this report. Of the 15 patients in the surgical group, 6 died and 9 survived. Of 19 in the non-surgical group, 5 died, 11 survived, and 3 were lost to follow-up.

Symptoms. The frequency and severity of symptoms were comparable in both groups (Fig. 1). A finding common to both groups was chest pain. In most, the pain was vague both in location and description and was unrelated to effort. In 4 patients a relation to exertion was noted, and in all 4 the pulmonary arterial pressure was moderately raised. Whether associated coronary artery disease was present was not determined.

Chronic cough was present in 12 patients, but recurrent upper respiratory infections and pneumonia were relatively uncommon. In only one subject was there evidence of severe bronchopulmonary disease. Haemoptysis was present in 3 patients in each group. Four patients in the surgical group and 2 in the non-surgical group had one or more episodes of syncope.

A history of rheumatic fever was elicited in 3 patients in the surgical group. Coexisting rheumatic valvulitis (mitral stenosis) was found in 2 of these patients, and in a third who had no history of rheumatic fever. The age of onset of atrial fibrillation could be determined in 11 patients and averaged 50 years in the surgical group and 58 years in the non-surgical group.

Physical Findings. The physical findings were also similar, with minor differences, between the two groups of patients (Fig. 2). Systemic hypertension was uncommon in both groups. It was associated with coarctation of the aorta in one patient in the non-surgical group whose blood pressure was $230 / 100 \mathrm{~mm}$. Hg. Cyanosis and clubbing were usual. Palpation of the praecordium disclosed increased right ventricular activity in most instances. A thrust at the left base was present in 11 and a palpable shock of pulmonary closure in 13 patients.

Auscultation of the praecordium disclosed two types of systolic murmurs. In most, a murmur was audible along the upper left sternal border. Intensity was usually grade 2 or 3 (scale 1 to 6 ) and the character of the murmur was invariably blowing or soft and not obstructive in quality. Eleven patients had a systolic murmur at the lower left sternal border. In 4, the murmur was pansystolic, increased with inspiration, and was considered compatible with tricuspid insufficiency. Less commonly, a murmur consistent with mitral insufficiency was audible at the apex.

Diastolic murmurs were of two types. In 4 patients, a murmur characteristic of semilunar valve insufficiency was present. The pulmonary arterial pressure was slightly to moderately raised in all, but no correlation could be made between the size of the main pulmonary artery at fluoroscopy and the presence of this murmur. Whether the murmur represented pulmonary or aortic insufficiency was not established. A murmur suggestive of mitral stenosis was present in 2 patients, one of whom had post-mortem confirmation of a stenotic mitral valve. In a third patient, unsuspected mitral stenosis was discovered at the time of surgical closure of the atrial septal defect. In 16 patients, a third heart sound or "flow murmur" was present along the 


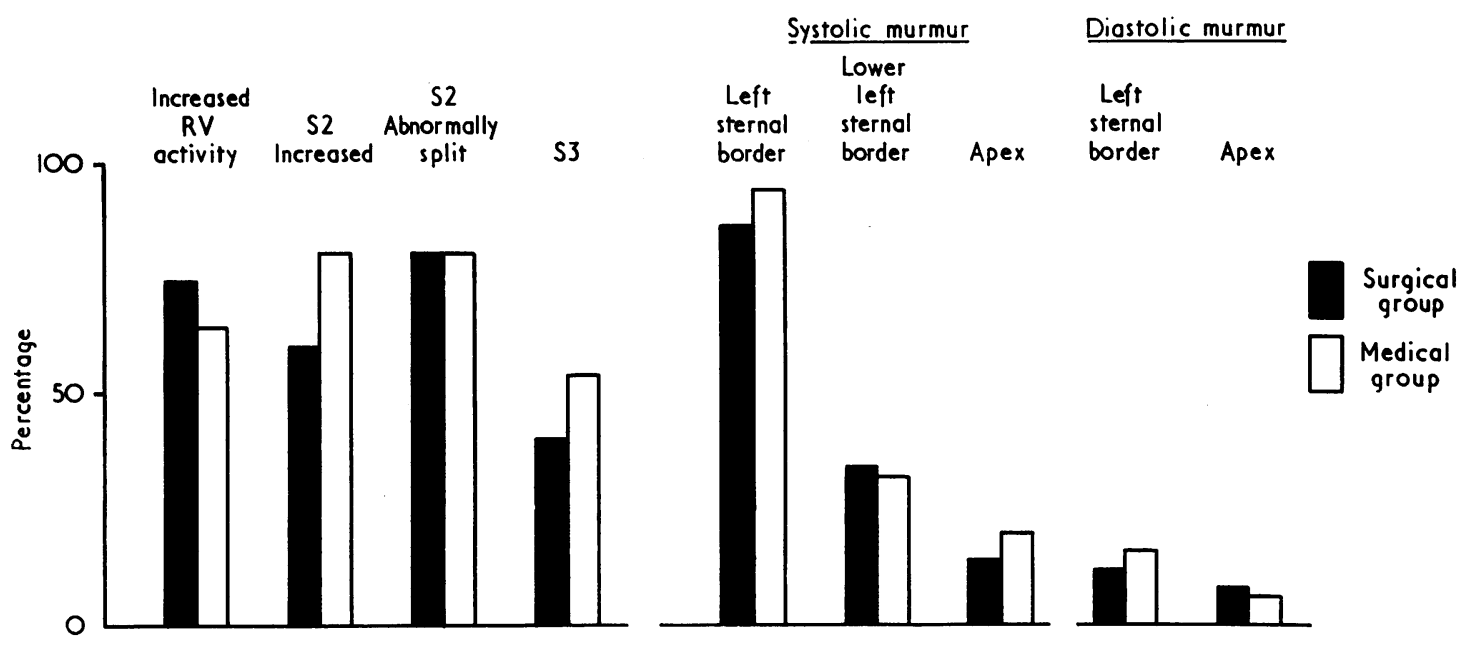

FIG. 2.-Physical findings in 15 patients who later underwent surgical closure of atrial septal defect and in 19 who received medical management.

lower left sternal border or at the apex but lacked sufficient duration or other features suggestive of mitral stenosis.

An early systolic ejection click was present in 5 patients and was heard maximally at the upper left sternal border in 4. No correlation could be made with the presence of pulmonary hypertension and the ejection click. None of the patients had valvular pulmonary stenosis. An ejection click was most prominent at the apex in the patient with coarctation of the aorta, suggesting an associated abnormality of the aortic valve.

The second heart sound typically was widely split and varied little with respiration. Phonocardiography, available in 4 of these patients, confirmed the abnormal splitting of the second sound with failure to close on expiration. The degree of splitting ranged from 0.035 to $0.045 \mathrm{sec}$. in one to 0.05 to $0.06 \mathrm{sec}$. in another. In one patient in each group the second sound was considered to split in a normal fashion; phonocardiography confirmed the normal degree of splitting $(0.02$ to $0.035 \mathrm{sec}$.) in one, while the tracing obtained in the other failed to exhibit two distinct components in the recording of the second sound. On auscultation, pulmonary closure was normal to accentuated, and its intensity correlated well with the presence or absence of pulmonary hypertension.

Hepatomegaly was present in 10 of the 19 patients in the non-surgical group and in 4 of the 15 in the surgical group. An enlarged spleen was palpable in $\mathbf{6}$ of the non-surgical group and in none of the surgical group.

Electrocardiographic Findings. The mean QRS axis was usually directed rightwardly and inferiorly in the frontal plane. In 4 patients, true left axis deviation $\left(270^{\circ}\right.$ to $\left.330^{\circ}\right)$ was present (to be discussed later) (Fig. 3). In 3 of these 4 patients, a secundum atrial septal defect was subsequently demonstrated at operation, while the location of the atrial septal defect remained unknown in the fourth patient.

The terminal QRS forces were analysed separately. In 23 patients, the terminal vector was directed rightwardly and anteriorly. In the right praecordial leads, four types of QRS complexes were noted (Fig. 4). In 9 patients of the surgical and in 8 of the non-surgical groups a large secondary $R$ wave was present (rsR'). Typical right bundlebranch block was present in 1 of the surgical and in 5 of the non-surgical groups. A qR or Rs pattern was less frequently seen. No correlation could be made between pulmonary arterial pressure, magnitude of left-to-right shunt, and type of QRS complex present.

Disturbances of rhythm were present in 12 of the 34 patients. Atrial fibrillation was present in 7 patients not operated upon and in 2 of those subjected to surgery. Other atrial arrhythmias included atrial flutter, atrial tachycardia, and wandering atrial pacemaker. First- and second-degree atrioventricular block were uncommon. Third-degree heart block was observed once and this occurred after operation. Ventricular premature contractions occurred in 9 patients and nodal prematurities in one.

Radiological Findings. (Fig. 5-8). Fluoroscopic examinations were made by one of us (S.G.B.) in 26 of the 34 patients. The over-all heart size was 


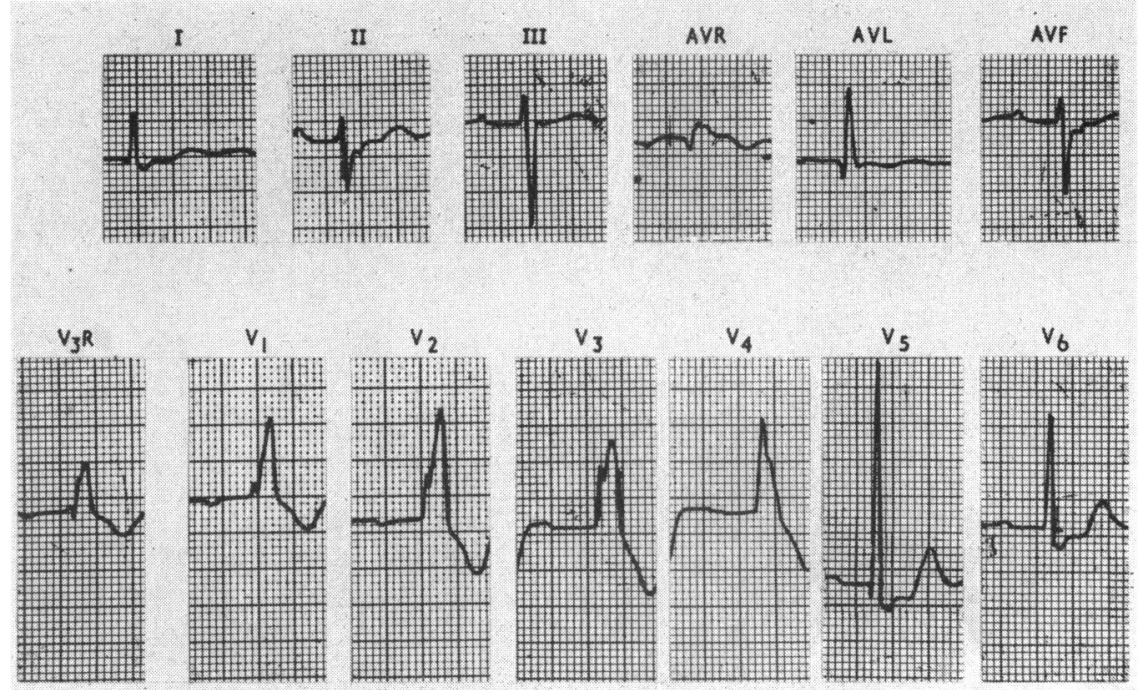

FIG. 3.-Electrocardiogram showing left axis deviation with right bundle-branch block. At operation an ostium secundum defect was demonstrated.

judged to be enlarged in 21 and normal in 2 patients (no comment on cardiac size was made in 3 instances). Left atrial and left ventricular enlargement were infrequent. Increased vascularity, vascular activity, and enlargement of the main

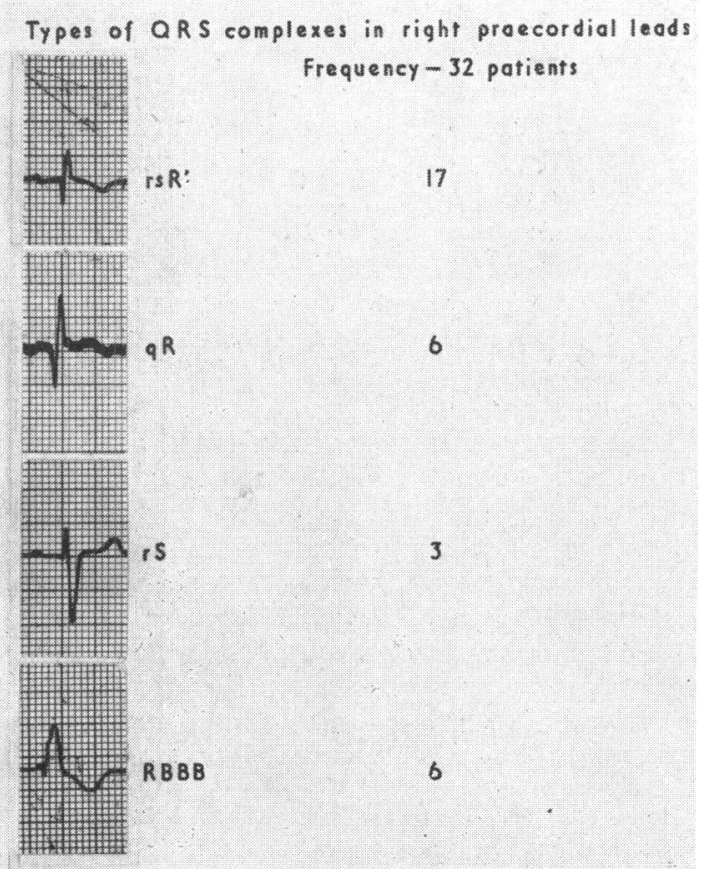

FIG. 4.-Four types of QRS complexes observed in right praecordial leads. pulmonary arteries were present in every case. In particular, an enlarged right pulmonary artery with an increased amplitude of pulsation often suggested the diagnosis in an otherwise unclear clinical setting. The aorta usually was normal or small in relation to the main pulmonary artery. In 2 patients the aorta was prominent, probably reflecting the uncoiling of the aorta commonly seen in older patients.

Cardiac Catheterization Findings. The haemodynamic data in the patients who were catheterized are summarized in the Table. Moderate peripheral arterial desaturation $(76 \%$ and $73 \%)$ was present in 2 patients of the non-surgical group and in none of the surgical group. The patients in the nonsurgical group tended to have higher pulmonary arterial pressures and pulmonary vascular resistances; however, most patients in both groups showed only modestly raised pulmonary arterial pressures with high pulmonary blood flows.

Operative Findings. The location of the defect was stated in 13 patients and in all instances was of the secundum variety. Most had large defects, ranging from $2 \times 2 \frac{1}{2}$ to $7 \times 5 \mathrm{~cm}$. in diameter. Repair with sutures was performed in 10 cases, with a patch in 3, and the procedure was not stated in 2 who had operations elsewhere. No associated defects were seen. Hypothermia and inflow occlusion techniques were used in 12, cardiopulmonary bypass was used in 2 , and this information was not available in one. 


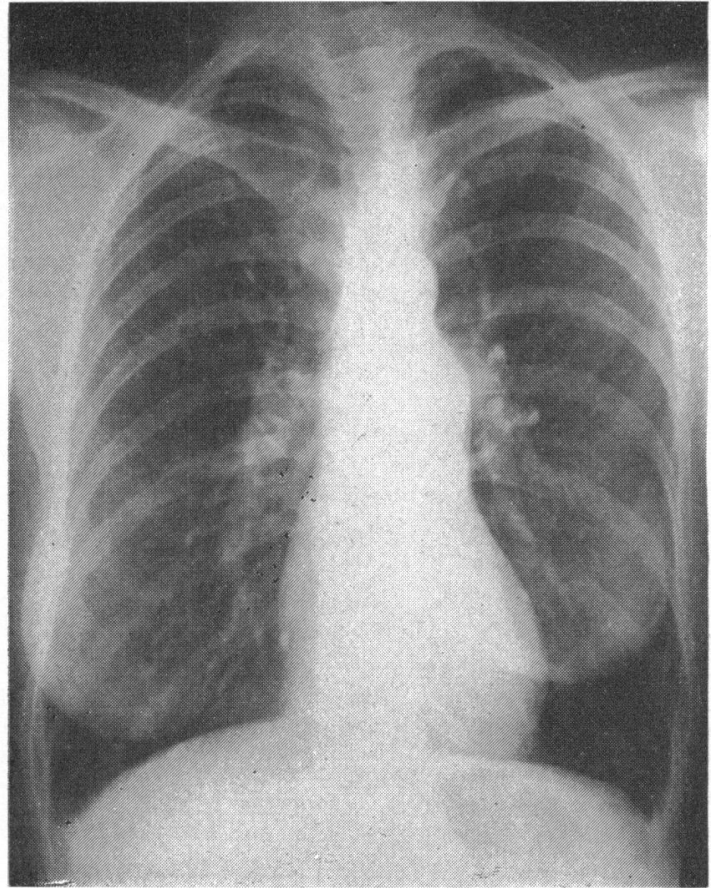

Fig. 5.- $X$-ray film of a patient aged 59, showing normal heart size and enlarged pulmonary arteries.

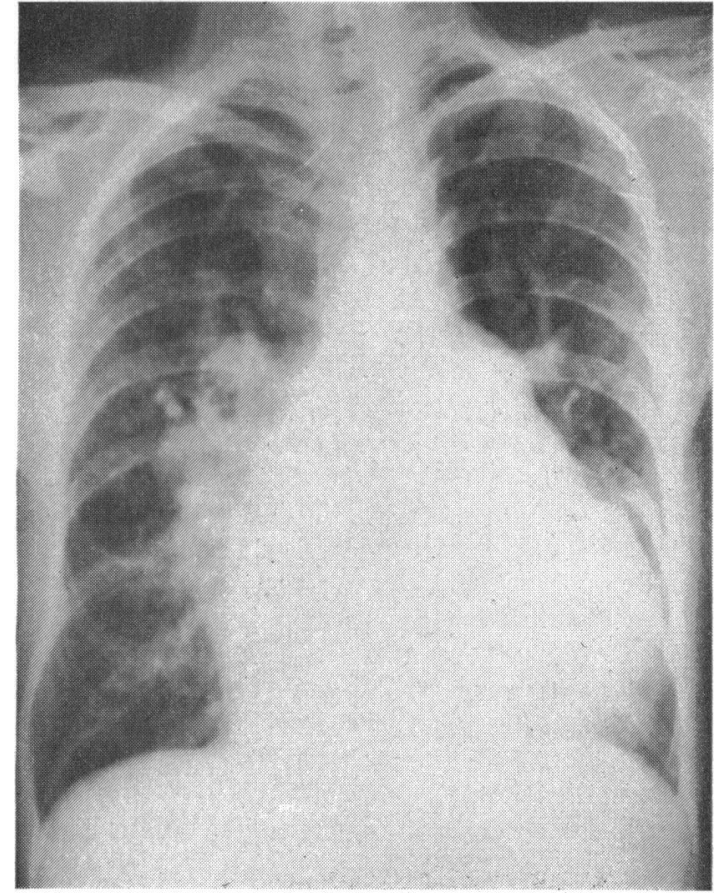

FIG. 6.- $X$-ray film of a patient aged 58 , showing considerable cardiac enlargement and increased pulmonary vascularity.

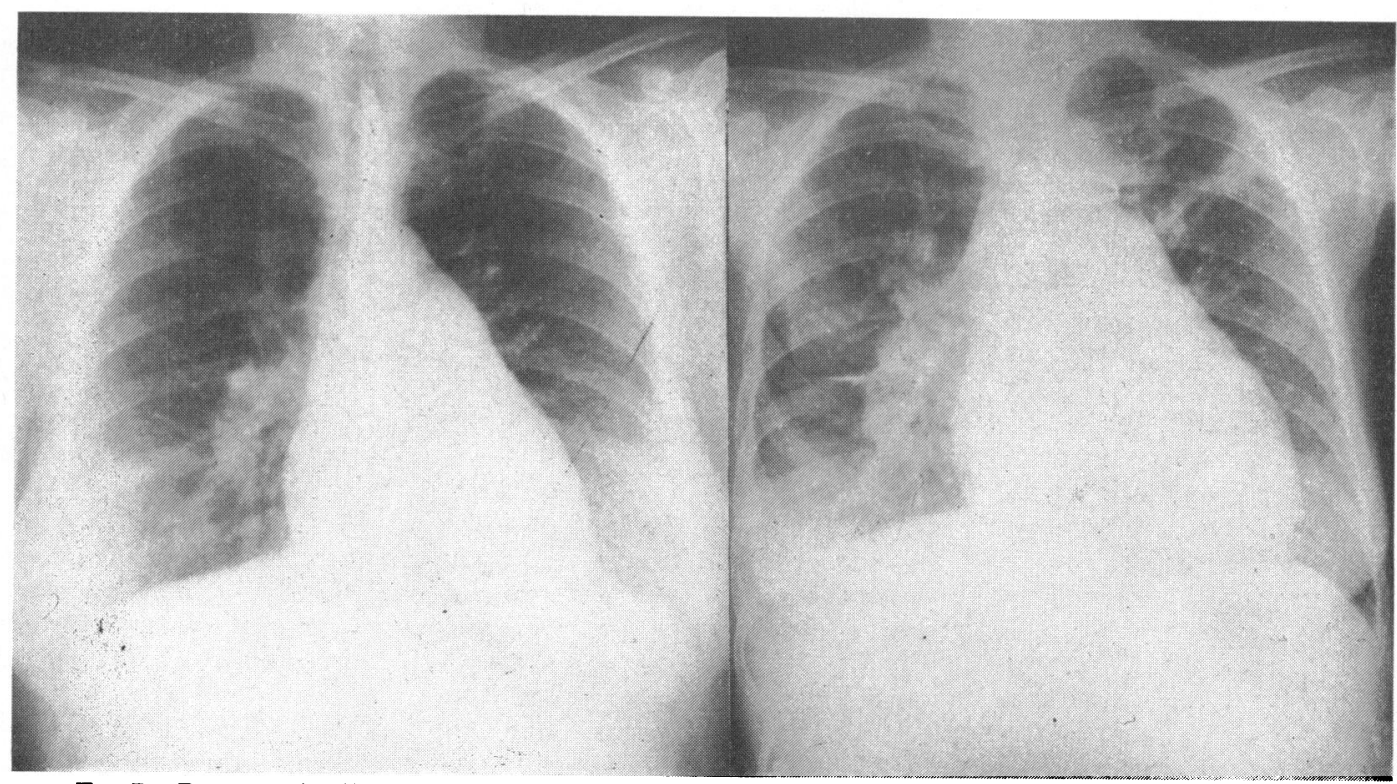

FIG. 7.-Pre-operative (left) and post-operative (right) $x$-ray films, in a patient showing no regression of cardiac enlargement 8 months after operation. 
TABLE

HAEMODYNAMIC DATA IN PATIENTS WHO WERE CATHETERIZED (3 PATIENTS ALSO CATHETERIZED POST-OPERATIVELY)

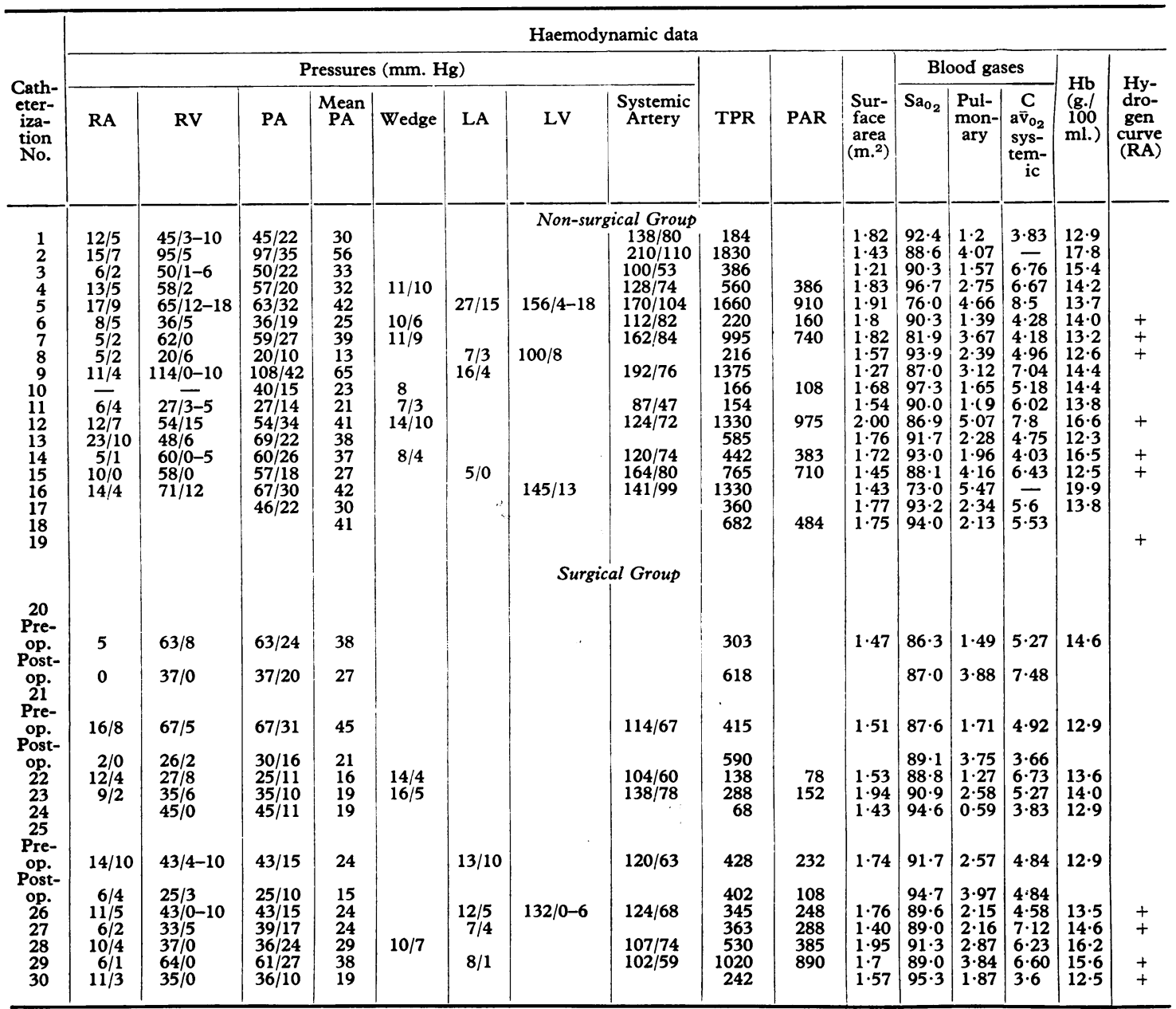

$\mathrm{Sa}_{\mathrm{O}_{2}}$ : Arterial oxygen saturation (\%). $\mathrm{Ca}_{\mathrm{v}_{2}}$ : Arteriovenous oxygen difference (vol. \%). TPR: Total pulmonary resistance (dynes sec. $\mathrm{cm} . \mathrm{-}^{-5} \mathrm{~m}^{2}$.). PAR: Pulmonary arteriolar resistance (dynes sec. $\mathrm{cm} .-^{5} \mathrm{~m}^{2}$.).

Post-operative Findings. Post-operative observations were available in 11 patients. They were usually recorded at the time of the patient's most recent evaluation, an interval which averaged $5 \frac{1}{2}$ years and ranged from 3 weeks to 10 years postoperatively. Ordinarily, several months were required for symptoms to regress following operation. Two patients with only mild symptoms before operation developed a conspicuous increase in symptoms after surgery.

After operation, dyspnoea was lessened in 6 and unchanged in 5 patients. Orthopnoea and paroxysmal nocturnal dyspnoea increased in 4 patients and occurred either in the immediate post-operative period or up to several years after operation. The persistence of easy fatiguability was observed in 5 of 10 patients who had this symptom before operation.

Persistence of an increased right ventricular lift was recorded on physical examination in 5 cases. Right ventricular enlargement was also observed by electrocardiography and fluoroscopy for as long as 3 years after operation. The systolic murmur at the upper left sternal border remained in 4 and decreased or became inaudible in 5 patients. A flow murmur disappeared in the 3 patients in whom it was heard before surgery. The second sound showed abnormal splitting with failure to close with expiration in 8 of 11 patients after surgery. An increased 


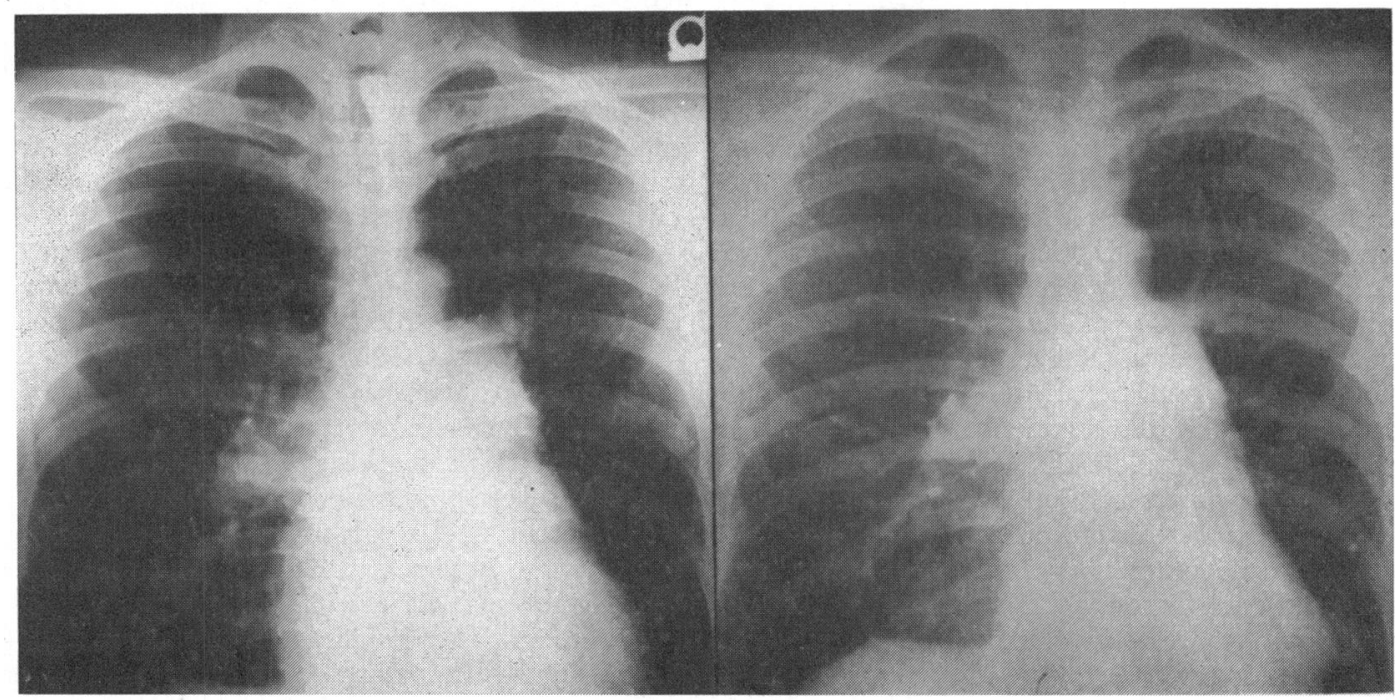

FIG. 8.-Pre-operative (left) and post-operative (right) $x$-ray films in a patient showing decrease in heart size 6 years after operation.

pulmonary component persisted in 5 of 8 patients. The foregoing observations on the second sound were recorded at intervals from 4 to 96 months after operation. No phonocardiographic observations were recorded either before or after operation.

The electrocardiogram correlated well with the post-operative physical findings. The QRS axis shifted to a normal position from a previously rightward axis in 3 patients. In 7, who had exhibited a normal or left axis, the mean QRS axis did not change appreciably. The configuration of the QRS complex in the right praecordial leads was unaffected by the surgical procedure, but the magnitude of the terminal rightward forces decreased in 5 patients. Right atrial enlargement regressed in 4 of 5 patients. Normal sinus rhythm was observed 10 times before operation and atrial fibrillation twice; after operation, 6 patients had sinus rhythm and 5 had atrial fibrillation.

Fluoroscopic findings in 6 patients postoperatively showed that the over-all heart size diminished in 4 and remained unchanged in 2. Right ventricular enlargement persisted in all, and in 5 the degree of right atrial enlargement was thought not to have changed significantly. In 4 patients the activity of the heart and main pulmonary arteries receded. Enlargement of the main pulmonary arteries persisted in 5 patients and decreased in one.

Cardiac catheterization in 3 patients before and after operation (Table), showed that pulmonary arterial pressure decreased in all but remained abnormally raised in one. A persistent left-to-right interatrial shunt was demonstrated in this patient who also had clinical and laboratory evidence of obstructive bronchopulmonary disease.

Post-operative Complications. In most patients the post-operative period was protracted and was characterized by one or both of two general complications. Respiratory problems predominated and included pneumonia, atelectasis, acute pulmonary oedema, and pulmonary embolism. Secondly, a variety of arrhythmias were observed, including atrial tachycardia, atrial fibrillation, atrial flutter, AV dissociation, and ventricular fibrillation. Two patients developed the "post-pericardiotomy syndrome", and only two had an uneventful postoperative recovery.

Six patients in the surgical group have died. Three died in the immediate post-operative period, 1 with ventricular fibrillation and 2 following a second attempt at closure of their defect. Of the remaining 3, 1 died a month after operation with necrotizing pneumonitis and respiratory insufficiency, 1 died seven years after operation with an acute myocardial infarction and mesenteric arterial occlusion accompanied by an embolus at the aortic bifurcation, and 1, who was considered to have benefited from surgery, was accidentally drowned six months after operation. In the non-surgical group, 5 are known to have died: 1 with congestive heart failure, 1 from pulmonary and systemic embolism, 2 with metastatic carcinoma, and 1 in whom the cause of death was not known; 3 were lost to follow-up. 
Post-mortem Findings. Necropsy data were available in 6 patients, 3 in each group. The over-all heart size, particularly the right ventricle, was enlarged in every case. Left ventricular enlargement was concomitantly present in 4 patients. A dilated tricuspid valve was noted in 3 , and in these 3 , a murmur consistent with tricuspid insufficiency had been noted. Coexisting rheumatic valvulitis with mitral stenosis and insufficiency was present in one patient. No other valvular lesions were seen.

The atrial septal defect was closed in the 3 patients who had undergone surgery. In the 3 patients managed medically, the defects measured $2 \cdot 5,1.5$, and $2 \mathrm{~cm}$. in their longest diameter.

Examination of the pulmonary vasculature disclosed multiple pulmonary emboli in 2 instances. Diffuse, severe pulmonary atherosclerosis occurred in 1 patient, moderate involvement in 3, and mild involvement in one. An acute infarction of the left and right ventricle, respectively, was responsible for the sudden deaths of 2 patients in the surgical group. The right ventricular infarct was observed at operation during which cardiopulmonary bypass had been employed. Coronary artery air embolism was suspected though not proven. Two patients developed systemic embolism, one of whom sustained the above-mentioned acute left ventricular infarct following closure of the atrial septal defect, while the other patient had evidence of thrombi in both atria at necropsy.

\section{Discussion}

Our surgical and non-surgical groups were similar in several respects. Symptoms, physical findings, electrocardiograms, and $x$-ray films disclosed no consistent differences between the two groups. Although cardiac catheterization revealed a higher incidence of pulmonary hypertension in the nonsurgical group, many patients in both groups had only slightly raised pulmonary arterial pressures.

Reports have indicated the feasibility of surgical closure of atrial septal defect in the elderly patient. Ellis et al. (1960) described 5 patients over 60 years of age who underwent surgical repair, all of whom survived with a good or excellent result. In a series reported by Taylor et al. (1963), 5 patients ranging from 42 to 59 years underwent successful surgical closure with no mortality. In a larger series of 115 patients, 38 of whom were 40 years of age and older, McGoon et al. (1959) observed that several factors affected the surgical mortality. If congestive heart failure was present, the mortality was 39 per cent. Of 10 patients with a peak right atrial pressure of $15 \mathrm{~mm}$. $\mathrm{Hg}$ or greater, $5 \mathrm{died}$, and in those with a right-to-left shunt of 10 per cent or greater, 7 of 14 patients died after operation. Those with a pulmonary arterial pressure of $75 \mathrm{~mm} . \mathrm{Hg}$ or higher had a mortality of 53 per cent, and in those with a ratio of pulmonary: systemic resistance of $1: 2$ or more, 5 of 7 died following operation.

That operation may adversely alter the natural history of atrial septal defect is supported by an analysis of 298 patients with secundum defects (Zaver and Nadas, 1965). Of these, 240 patients underwent operation and 23 died as a direct result of the operation. Among the 23 deaths, 17 occurred in patients with congestive heart failure or with evidence of severe pulmonary vascular disease.

At present, in our non-surgical group, 11 patients are known to be alive and 3 have been lost to followup. Nine have either minimal or no symptoms, and 2 are mildly to moderately symptomatic. Five have died, 2 with metastatic carcinoma. Two died of cardiovascular causes: 1 with pulmonary and systemic embolism and 1 with severe congestive heart failure. Among those surgically treated, there were 3 immediate operative deaths. Two patients died at intervals of one and six months and 1 at seven years following operation. Of the 9 survivors, 2 have had progression of their symptoms, and 7 have become asymptomatic. Five of the latter 7 patients were mildly and 2 severely symptomatic before.

Two factors may explain the adverse effects of surgery in several of these patients. Many underwent repair before the advent of cardiopulmonary bypass. Two such patients required a second corrective procedure and died immediately after the second operation. A third, who remained severely symptomatic after operation, had a persistent interatrial shunt on repeat catheterization. Presumably operation using cardiopulmonary bypass would have resulted in more effective closure at the initial operation in these patients. Secondly, the postoperative morbidity has lessened as more experience has been gained in the management of pulmonary complications, thrombo-embolism, arrhythmias, and fluid balance derangements. The greater frequency of these problems in the older adult has clearly decreased following other types of open-heart surgery. Survival in the present series might have been favoured by improved techniques in postoperative management.

Thus, while there is little doubt about advising operation in the younger patient with atrial septal defect, the role of operation in the middle-aged patient remains uncertain. However, certain assumptions seem valid. First, a substantial operative risk exists for the patient with severe pulmonary hypertension, and considerable morbidity may per- 
sist after operation. In contrast there are patients who have reached advanced age with few or no symptoms. They are represented by several in the present series, and for such patients conservative management appears indicated. A number of symptomatic older persons remain in whom pulmonary arterial pressures are mildly to moderately raised. Surgical closure may offer the greatest hope for this group, though the long-term benefit of an operation that decreases symptoms and prolongs survival has not been determined.

We have recently observed a case in which an interatrial communication may have served to protect a hypoplastic right ventricle and in which right ventricular failure supervened following closure of the defect (Overy, Steinbicker, and Blount, 1966). The patient was a 4-year-old boy with persistent left superior vena caval drainage into the left atrium. A considerable right-to-left interatrial shunt was present before operation, presumably because the under-developed right ventricle offered increased resistance to filling. Closure of the defect resulted in increased right ventricular filling and led to right ventricular failure.

An analogous situation may apply to the adult with a large atrial septal defect. The circumstance of a long-standing left-to-right shunt may allow the left ventricle to become relatively small and hypoplastic. As noted by Dexter (1956), such a ventricle is less able to tolerate superimposed burdens such as systemic hypertension, mitral insufficiency, or coronary artery disease, and the ventricular diastolic pressure may rise. The interatrial defect then functions as an "escape valve", permitting the increased ventricular diastolic pressure to be manifested by an increased left-to-right shunt. Closure of the defect in such a patient could then lead to pulmonary venous hypertension and pulmonary oedema. It is of interest that one of the patients reported by Tikoff et al. (1965) developed heart failure following closure of an atrial septal defect. Similarly, one of our patients developed pulmonary oedema after operation, while orthopnoea and paroxysmal nocturnal dyspnoea remained as troublesome symptoms in 3 other patients after operation.

The location of the atrial septal defect can usually be reliably predicted from the electrocardiogram. Specifically, Pryor, Woodwark, and Blount (1959) and Burchell, DuShane, and Brandenburg (1960) found that most defects of the ostium primum type were associated with left axis deviation, while normal or rightward QRS forces in the frontal plane were the rule with secundum defects. Only rarely has such deviation been recorded with ostium secundum lesions (Harrison and Morrow, 1963). In this series, 4 patients showed left axis deviation,
3 of whom had proven secundum defects. In adults, left axis deviation is usually associated with acquired disease (fibrosis) of the left ventricle, chiefly affecting the fibres of the superior radiation of the left conduction bundle (Hawley and Pryor, 1965). In the 4 patients cited herein, it is probable that left axis deviation resulted from acquired left ventricular disease rather than from a congenital deformity of the conduction network.

\section{SUMMARY}

Studies were made on 34 patients over age 45 years with atrial septal defects. Surgical closure was carried out in 15 and medical management in 19. There were 6 deaths among those undergoing surgery, 3 immediately and 3 at one month, six months, and seven years after operation. Two had increasing disability after surgery, while 7 obtained benefit from the operation. In contrast, 11 of those not operated upon have minimal or no symptoms despite an average age 10 years in excess of the surgical group. Only 3 patients in this group died from cardiovascular complications; 3 were lost to follow-up.

Merits of surgery in the older adult with atrial septal defect in this and other series have been reviewed. In patients with severe pulmonary hypertension, the operative risk is high and the post-operative morbidity may be disabling. Consservative management may also be appropriate for the occasional asymptomatic elderly patient. Surgery appears to offer greatest benefit to the progressively symptomatic adult with normal or mild to moderate increases in pulmonary arterial pressure.

\section{REFERENCES}

Burchell, H. B., DuShane, J. W., and Brandenburg, R. O. (1960). The electrocardiogram of patients with atrioventricular cushion defects (defects of the atrioventricular canal). Amer. F. Cardiol., 6, 575.

Cherniack, N. S. (1963). A study of the frequency of associated cardiac and pulmonary disease in patients with defects of the atrial septum coming to necropsy. Dis. Chest, 43, 397.

Colmers, R. A. (1958). Atrial septal defects in elderly patients. Report of three patients aged 68, 72, and 78 . Amer. F. Cardiol., 1, 768.

Dexter, L. (1956). Atrial septal defect. Brit. Heart f., 18, 209.

Ellis, F. H., Jr., Brandenburg, R. O., and Swan, H. J. C. (1960). Defect of the atrial septum in the elderly. Report of successful surgical correction in five patients sixty years of age or older. New Engl.F. Med., 262, 219.

Harrison, D. C., and Morrow, A. G. (1963). Electrocardiographic evidence of left-axis deviation in patients with defects of the atrial septum of the secundum type. New Engl. F. Med., 269, 743. 
Hawley, R. L., and Pryor, R. (1965). Quantitative and electrocardiographic correlation of the conduction system of the heart (abstract). Amer. F. Cardiol., 15, 132.

Kelly, J. J., Jr., and Lyons, H. A. (1958). Atrial septal defect in the aged. Ann. intern. Med., 48, 267.

McGoon, D. C., Swan, H. J. C., Brandenburg, R. O., Connolly, D. C., and Kirklin, J. W. (1959). Atrial septal defect: Factors affecting the surgical mortality rate. Circulation, 19, 195.

Novack, P., Segal, B., Kasparian, H., and Likoff, W. (1963). Atrial septal defect in patients over forty. Geriatrics, $18,421$.

Overy, H. R., Steinbicker, P. G., Jr., and Blount, S. G., Jr. (1966). Anomalous systemic venous drainage with hypoplasia of the right ventricular myocardium. Circulation, 33, 613.

Pryor, R., Woodwark, G. M., and Blount, S. G., Jr. (1959). Electrocardiographic changes in atrial septal defects: Ostium secundum defect versus ostium primum (endocardial cushion) defect. Amer. Heart f., 58, 689.
Rodstein, M., Zeman, F. D., and Gerber, I. E. (1961). Atrial septal defect in the aged. Circulation, 23, 665.

Roesler, H. (1934). Interatrial septal defect. Arch. intern. Med., 54, 339.

Taylor, F. H., Sanger, P. W., and Robicsek, F. (1963). Atrial septal defects in older patients. Report of five cases with successful surgical repair. Collected Works Cardio-pulm. Dis. (Charlotte Memorial Hospital, N.C.), 7-8, 381.

Tikoff, G., Schmidt, A. M., Kuida, H., and Hecht, H. H. (1965). Heart failure in atrial septal defect. Amer. $\mathcal{F}$. Med., 39, 533.

Van Slyke, D. D., and Neill, J. M. (1924). The determination of gases in blood and other solutions by vacuum extraction and manometric measurement. $\mathcal{f}$. biol. Chem., 61, 523.

Zaver, A. G., and Nadas, A. S. (1965). Atrial septal defectsecundum type. Circulation, 31 and 32, Suppl. 3, 24. (Amer. Heart Ass. Monogr. No. 12.) 